\title{
ANALISIS GARAP LANCARAN GAGAK SETRA DALAM PAKELIRAN GAYA YOGYAKARTA
}

\author{
Amrih Tuti Lestari \\ Institut Seni Indonesia Yogyakarta, Jalan \\ Parangtritis Km. 6,5, Sewon Bantul Yogyakarta \\ 55001, Indonesia \\ amrihsmki2016@gmail.com
}

\author{
Bayu Wijayanto \\ Institut Seni Indonesia Yogyakarta, Jalan \\ Parangtritis Km. 6,5, Sewon Bantul Yogyakarta \\ 55001 , Indonesia \\ etnopeter@gmail.com
}

\author{
R. Bambang Sri Atmojo \\ Institut Seni Indonesia Yogyakarta, Jalan \\ Parangtritis Km. 6,5, Sewon Bantul Yogyakarta \\ 55001, Indonesia \\ bambangsriatmojo0405@gmail.com
}

dikirim 13 Oktober 2021; diterima 25 Februari 2022; diterbitkan 01 Maret 2022

\begin{abstract}
Abstrak
Penelitian dengan judul Lancaran Gagak Setra Dalam Pakeliran Gaya Yogyakarta membahas mengenai pathet, garap, struktur penyajian, struktur pertunjukan, serta transisi pathet Lancaran Gagak Setra pada adegan budhalan dalam pakeliran gaya Yogyakarta. Penelitian ini menggunakan pendekatan penelitian kualitatif dengan metode penelitian deskriptif analisis dengan menganalisis pada dua konteks yaitu tekstual dan kontekstual. Analisis tekstual pada penelitian ini menganalisis pathet, transisi pathet Lancaran Gagak Setra dalam pakeliran gaya Yogyakarta, faktor musikal yang dipertimbangkan dalam transisi pathet, dan struktur sajian Lancaran Gagak Setra dalam pakeliran lakon Suryatmaja Krama dengan menganalisis garap dari beberapa ricikan. Analisis kontekstual menganalisis struktur pertunjukan Lancaran Gagak Setra pada adegan budhalan dalam lakon Suryatmaja Krama. Gagak Setra merupakan salah satu lancaran yang digunakan dalam adegan budhalan dengan kapalan atau jaranan pada pakeliran gaya Yogyakarta. Lancaran Gagak Setra dalam pakeliran gaya Yogyakarta disajikan dalam ranah waktu pathet nem namun, balungan gending Lancaran Gagak Setra lebih menitikberatkan pada pathet sanga. Perbedaan pathet dalam ranah waktu penyajian tersebut mengakibatkan perbedaan anggapan pathet pada Lancaran Gagak Setra. Penyajian Lancaran Gagak Setra dalam pakeliran yang berbeda pathet tentunya terdapat transisi pathet. Transisi pathet tersebut terdapat faktor musikal yang dipertimbangkan yaitu Bendhe Tengara menjadi transisi dari pathet manyura ke pathet sanga serta grambyangan menjadi transisi dari pathet sanga ke pathet nem. Kedua faktor musikal tersebut akan menjadikan transisi antara pathet nem, manyura, sanga, dan nem terjadi secara perlahan atau gradual dan tercapai rasa pathet dari Lancaran Gagak Setra yang mendukung suasana dramatik pada adegan budhalan dengan kapalan pada pakeliran gaya Yogyakara.
\end{abstract}

Kata Kunci: Lancaran Gagak Setra, budhalan, pathet, transisi pathet.

This work is licensed under a Creative Commons Attribution-ShareAlike 4.0

\section{Abstract}

The research entitled Lancaran Gagak Setra in Pakeliran Gaya Yogyakarta discusses pathet, garap, presentation structure, performance structure, and the transition of pathet Lancaran Gagak Setra in the budhalan scene in pakeliran style in Yogyakarta. This study uses a qualitative research approach with descriptive analysis research methods by analyzing in two contexts, namely textual and contextual. The textual analysis in this study analyzes the pathet, the transition of Lancaran Gagak Setra in the Yogyakarta style pakeliran, the musical factors considered in the pathet transition, and the structure of the Lancaran Gagak Setra presentation in the Suryatmaja Krama theater play by analyzing the work of several ricikan. Contextual analysis analyzes the structure of the Lancaran Gagak 
Setra performance in the budhalan scene in the Suryatmaja Krama play. Gagak Setra is one of the genres used in the budhalan scene with calluses or jaranan in the Yogyakarta style pakeliran. Lancaran Gagak Setra in the Yogyakarta style pakeliran is presented in the realm of pathet nem time, however, the balungan gending Lancaran Gagak Setra focuses more on pathet sanga. The difference in pathet in the realm of presentation time results in differences in the perception of pathet in Lancaran Gagak Setra. The presentation of the Lancaran Gagak Setra in different packages, of course, has a pathet transition. There are musical factors to consider in this pathet transition. Bendhe Tengara is the transition from pathet manyura to pathet sanga, and grambyangan is the transition from pathet sanga to pathet nem. These two musical factors will make the transition between pathet nem, manyura, sanga, and nem happen slowly or gradually. A sense of pathet is achieved from Lancaran Gagak Setra, which supports the dramatic atmosphere in the budhalan scene with calluses in the Yogyakarta-style pakeliran.

Keywords: Lancaran Gagak Setra, budhalan, pathet, pathet transition

\section{Pendahuluan}

Gagak Setra merupakan gending berbentuk lancaran yang digunakan dalam karawitan pakeliran gaya Yogyakarta. Karawitan pakeliran merupakan salah satu unsur penting dari garap pakeliran. Karawitan pakeliran adalah semua bunyi vokal maupun ricikan yang digunakan untuk menghidupkan susana dalam pertunjukan wayang yang meliputi: sulukan, dhodhogan, keprakan, tembang, dan gending (Soetarno 2007). Gending merupakan kumpulan nada-nada yang disusun menjadi sebuah lagu yang kemudian diatur menjadi sebuah bentuk tertentu. Gending di dalam pakeliran bersifat mungkus (membingkai), nglambari (ilustrasi), dan nyawiji (Waridi 2005, 17-19) (Junaidi and Sugiarto 2018). Merujuk dari penjelasan tersebut, bahwa Lancaran Gagak Setra bersifat membingkai salah satu adegan pada pakeliran gaya Yogyakarta.

Pakeliran gaya Yogyakarta terbagi menjadi beberapa adegan. Pembagian adegan didasarkan pada nada dasar iringan atau disebut dengan pathet, yang terbagi menjadi: pathet nem, sanga, dan manyura. Trustho (K.M.T. Radyobremoro) berpendapat bahwa pathet memiliki dua pengertian yaitu waktu berdasarkan pada pakeliran dan pembatasan berdasarkan pada garap serta pembatasan pada wilayah nada. Berdasarkan pendapat tersebut memang setiap gending yang disajikan dalam pakeliran yang terbingkai dalam suatu pathet maka akan ditentukan waktunya. Lancaran Gagak Setra dalam pakeliran gaya Yogyakarta digunakan pada adegan budhalan untuk kapalan. Budhalan merupakan adegan yang menggambarkan situasi dan suasana keberangkatan para prajurit, sebagian menunggang kuda, menari mengikuti irama tertentu (Sumarsam 2018). Adegan Budhalan termasuk dalam ranah waktu pathet nem.

Penyajian Lancaran Gagak Setra dalam pakeliran didahului dengan sajian kawin. Kawin yaitu vokal dari seorang dalang dengan diiringi oleh beberapa ricikan gamelan seperti: gender, kempul, dan gong yang diikuti dengan dhodogan banyu tumetes. Kawin yang mendahului Lancaran Gagak Setra yaitu Kawin Sekar Asmarandana laras slendro pathet manyura dilanjutkan dengan Bendhe Tengara setelah Bendhe Tengara kemudian dilanjutkan Kawin Sekar Pangkur laras slendro pathet sanga. Urutan sajian kawin tersebut hanya digunakan ketika Lancaran Gagak Setra disajikan yaitu ketika adegan budhalan dengan menggunakan kapalan. Lancaran Gagak Setra disajikan setelah urutan sajian kawin yang disesuaikan dengan kebutuhan dari seorang dalang menggunakan sasmita gending "kadya dhandhang alelumbungan".

Lancaran Gagak Setra dalam pakeliran gaya Yogyakarta terbingkai dalam ranah waktu slendro pathet nem. Terdapat beberapa asumsi serta penelitian terdahulu yang menyatakan Lancaran Gagak Setra berlaras slendro pathet nem. Menurut Margiyono Lancaran Gagak Setra termasuk dalam pathet nem karena disajikan dalam ranah waktu pathet nem yang menyesuaikan dengan ranah pathetnya. Namun, ada beberapa asumsi pula yang menyatakan bahwa Lancaran 
Gagak Setra berlaras slendro pathet sanga. Menurut Marsudi Sanyoto Lancaran Gagak Setra berlaras slendro pathet nem yang dalam penerapannya digarap dalam pathet sanga karena akan lebih rumit jika digarap dalam pathet nem. Lancaran Gagak Setra dilihat dari struktur balungan gending lebih menguatkan pada pathet sanga serta beberapa asumsi pula yang menyatakan bahwa Lancaran Gagak Setra berlaras slendro pathet sanga. Pathet nem bernada dasar atau dhong pada nada 2 (gulu) sedangkan pathet sanga bernada dasar atau dhong pada nada 5 (lima), dan pathet manyura bernada dasar atau dhong 6 (enem) (Martopangrawit 1975). Lancaran Gagak Setra dilihat dari struktur balungan pada setiap seleh suwukan bernada 5 (lima) yang menguatkan pada pathet sanga. Pertunjukan wayang kulit yang telah terbagi waktunya berdasarkan pathet seperti halnya adegan budhalan yang memang dalam ranah waktu pathet nem akan tetapi Lancaran Gagak Setra memiliki ketidak-laziman pada pathet nem seperti biasanya. Ketidak-laziman tersebut terletak pada nada dasar atau dhong 5 (lima) yang menitik-beratkan pada pathet sanga.

Penelitian ini merujuk pada salah satu lakon dalam pertunjukan wayang kulit purwa gaya Yogyakarta, yaitu lakon Suryatmaja Krama. Pemilihan lakon Suryatmaja Krama dirasa cocok dengan karakter dari lancaran. Lancaran Gagak Setra dilihat dari nada dhong menitik-beratkan pada pathet sanga dengan karakter gembira. Karakter gending tersebut terbagi berdasarkan pathet yaitu: slendro nem berkarakter tenang, luhur dan wingit, slendro sanga berkarakter gembira, gagah, dan kuat, slendro manyura berkarakter gembira, luruh, tidak begitu kuat (Soeroso 1985). Gending dalam pakeliran berperan menghidupkan adegan baik dalam suasana agung, gembira, susah, terenyuh, bantah-binantah, dan perang (Bambang Sri Atmojo 2011). Lancaran Gagak Setra menghidupkan suasana adegan saat para tokoh budhal untuk mengiringi calon pengantin dengan suasana hati gembira. Naskah Lampahan Suryatmaja Krama ditulis ulang oleh Ki Udreko Hadi Swasana yang kemudian dijadikan sebagai sumber acuan dalam penelitian Lancaran Gagak Setra dalam Pakeliran Gaya Yogyakarta.

Ruang pathet nem dan ruang pathet sanga terdapat sekat dan pintu yang cukup (Budi Prasetya 2012). Perasaan musikal seseorang tidak mudah keluar masuk dalam kedua pathet tersebut. Dengan demikian, penyajian Lancaran Gagak Setra perlu adanya transisi pathet agar perubahan pathet terjadi secara perlahan atau gradual. Fenomena yang terjadi pada Lancaran Gagak Setra tersebut perlu adanya penelitian lebih lanjut, maka penulis mengangkat fenomena ini menjadi topik penelitian. Penelitian ini difokuskan pada analisis pathet, garap, dan transisi pathet. Analisis pathet dari Lancaran Gagak Setra dalam pakeliran yang berfokus pada ricikan rebab, gender, vokal (sindhenan).

Permainan ricikan balungan dalam menggarap suatu gending tentunya dipimpin oleh pamurba irama maka penulis menganalisis ricikan kendang dan bonang barung sebagai penentu dalam perubahan irama. Penelitian ini berfokus pada gaya Yogyakarta karena Lancaran Gagak Setra memang menjadi salah satu gending untuk kapalan di pakeliran gaya Yogyakarta. Gaya merupakan ciri khas suatu daerah sehingga pada permainan gamelan tentunya gaya Yogyakarta memiliki perbedaan dengan gaya pada wilayah yang lain maka, penulis menganalisis peking dan bonang penerus sebagai ciri khas tabuhan ricikan balungan dari gaya Yogyakarta. Ketika Lancaran Gagak Setra disajikan dalam bingkaian pathet nem namun balungan gending menitikberatkan pada pathet sanga tentunya terdapat faktor musikal yang dipertimbangkan dalam transisi pathet agar perubahan terjadi secara perlahan dan tercapai rasa pathet dari Lancaran Gagak Setra yang akan menghidupkan suasana dalam adegan budhalan. Faktor musikal yang dipertimbangkan dalam 
transisi pathet pada sajian Lancaran Gagak Setra, akan diteliti pada struktur budhalan dalam lakon Suryatmaja Krama yang telah disajikan oleh Ki Udreko Hadi Swasana.

\section{Metode}

Metode yang dilakukan penulis yakni metode deskriptif analisis, dengan analisis musikal pada dua konteks yaitu analisis tekstual dan analisis kontekstual. Analisis tekstual dari penelitian ini yaitu menganalisis pathet, garap, transisi pathet Lancaran Gagak Setra, faktor musikal yang dipertimbangkan dalam transisi pathet, dan penyajian Lancaran Gagak Setra dalam pakeliran lakon Suryatmaja Krama dengan menganalisis dari beberapa ricikan. Analisis kontekstual dengan menganalisis struktur pertunjukan Lancaran Gagak Setra dalam Lakon Suryatmaja Krama. Analisis tekstual akan menitik-beratkan pada pathet sanga dan analisis kontekstual akan menitik-beratkan pada pathet nem.

\section{Pembahasan}

Gagak Setra dalam Baoesastra Djawa Poerwadarminta kata "gagak" berarti burung dengan bulu berwarna hitam. Gagak Setra menjadi serangkaian nama lancaran yang berarti sekumpulan burung gagak berwarna hitam. Menurut sajian gendingya, lancaran tersebut dapat digunakan dalam berbagai sajian garap. Sajian garap tersebut diantaranya yaitu garap uyon-uyon dan garap wayangan. Lancaran Gagak Setra dalam garap wayangan tentunya terdapat perbedaan dengan garap uyon-uyon. Pada garap uyon-uyon berfokus pada garap gending yang disajikan tanpa terikat oleh pertunjukan seni lain, sedangkan dalam garap wayangan Lancaran Gagak Setra berfungsi sebagai pendukung pertunjukan wayang kulit purwa. Perbedaan sajian tersebut akan menjadi penentu sebuah garap. Penelitian ini berfokus pada garap wayangan yang digunakan dalam adegan budhalan dengan kapalan. Wayang terbagi dalam berbagai ragam jenis diantaranya: wayang beber, wayang golek, wayang orang, wayang kulit, wayang kertas, dan sebagainya (Junaidi 2011). Lancaran Gagak Setra pada penelitian ini digunakan dalam pertunjukan wayang kulit purwa khususnya gaya Yogyakarta. Wayang kulit purwa berarti wayang zaman dahulu (Sri Mulyana 1978). Gaya adalah ciri khas yang membedakan wayang kulit dari satu wilayah Jawa ke satu wilayah yang lain (Umar Kayam 2001).

Adegan budhalan disajikan dalam ranah waktu pathet nem. Adapun beberapa adegan yang disajikan dalam ranah waktu pathet nem yaitu Jejer kaping setunggal, Kondhur Kedhaton, Paseban Jawi, Budhalan, Perang Ampyak, Jejer kaping kalih, Jejer kaping tiga. Penelitian ini berfokus pada adegan Paseban Jawi, Kondhur Kedhaton, Budhalan, dan Perang Ampyak. Berdasarkan sajiannya Lancaran Gagak Setra disajikan dalam bingkai pathet nem sehingga dalam pakeliran lancaran tersebut dianggap dalam pathet nem. Analisis kontekstual pada penelitian ini menitik-beratkan bahwasannya Lancaran Gagak Setra berlaras slendro pathet nem dilihat dari penyajian Lancaran Gagak Setra yang disajikan dalam adegan pathet nem, namun terdapat beberapa asumsi serta balungan gending yang menitik-beratkan pada pathet sanga sehingga dalam penerapanya lancaran tersebut perlu adanya transisi pathet.

Pada Lakon Suryatmaja Krama Lancaran Gagak Setra disajikan dalam adegan budhalan. Lakon Suryatmaja Krama menceritakan pernikahan Dewi Surtikanthi dengan Raden Suryatmaja yang terbentang dari jejer kaping setunggal hingga kaping pitu. Adegan budhalan menceritakan persiapan prajurit Negara Ngastina yang akan berangkat ke Negara Mandaraka. Dalam 
penyajiannya Lancaran Gagak Setra dimulai dari sasmita gending "kadya dhandhang alelumbungan" kemudian dhodhogan mlatuk yang dilakukan oleh dalang yang kemudian buka dilakukan oleh bonang barung katampen kendang dengan menggunakan kendhangan bubaran atau lancaran irama II, dhodhogan masih terus dilakukan dan dilanjutkan dengan keprakan. Irama II digunakan untuk budhalan para tokoh kurawa dan prajurit. Wayang dicabut dari gedebok diurutkan dari sisi kiri yaitu Raden Aswatama, Raden Citraksa, Raden Citraksi, kemudian dilanjutkan pada sisi kanan yaitu Raden Durmagati, Raden Kartamarma, kemudian laya diajukan menjadi irama I dengan menggunakan keprakan cègcègcèg pada suwukan kedua gatra pertama dan kedua. Setelah gending menjadi irama I kemudian Raden Arya Dursasana dengan berjoget, kemudian Patih Sengkuni.

Setelah semua selesai, Raden Aswatama keluar memberi aba-aba prajurit kemudian ringgit rampogan keluar dipimpin Aswatama. Dursasana keluar berjoget bergantian dengan ringgit rampogan, setelah rampogan keluar kemudian tanceb di sisi kiri, gending menjadi irama II perubahan pada suwukan keempat. Irama II digunakan untuk kapalan yaitu Raden Aswatama dengan menaiki kuda diiringi prajurit dan berjoget, setelah berjoget dengan masih menaiki kuda gending diajukan laya, menjadi irama I dengan keprakan cègcègcèg pada suwukan ketiga. Setelah laya berubah menjadi irama I kemudian ringgit Kartamarma dan ringgit rampogan keluar dari sebelah kiri, ringgit rampogan masuk satu putaran kemudian dua kayon tancep di sisi kiri dan laya semakin seseg pada suwukan keempat untuk keluar ringgit rampogan dan tanceb di gedebok sisi kanan berhadapan dengan gunungan (kayu dan yang menghalangi jalan) bersamaan dengan suwuk gropak dan dilanjutkan antawacana untuk rampogan dengan dhodhogan geter. Lancaran Gagak Setra disajikan setelah Kawin Sekar Pangkur laras slendro pathet sanga dalam ranah waktu pathet nem.

\section{A. Transisi Pathet Lancaran Gagak Setra Dan Faktor Musikal Yang Dipertimbangkan Dalam Transisi Pathet}

Analisis tekstual dari penelitian ini menganalisis pathet, garap, transisi pathet Lancaran Gagak Setra, faktor musikal yang dipertimbangkan dalam transisi pathet, dan struktur sajian Lancaran Gagak Setra dalam pakeliran lakon Suryatmaja Krama dengan menganalisis dari beberapa ricikan. Pathet merupakan suatu hal yang tidak dapat dipisahkan dalam garap penyajian suatu gending. Pathet menjadi pembatas bagi garap serta pembatas bagi wilayah nada. Eksistensi pengrawit dalam menggarap sebuah gending akan dibatasi oleh pathet. Penyajian suatu gending yang dibingkai dalam suatu pathet, dan apabila gending tersebut disajikan dalam bingkai pathet lain tentunya terdapat suatu hal yang menjadi transisi pathet agar gending tersebut dapat masuk dalam rasa pathet lain. Dalam dunia karawitan apabila telah disajikan suatu gending dan akan menyajikan gending dengan pathet berbeda, maka perlu adanya transisi agar gending kedua dapat dicapai rasa pathet dan transisi terjadi secara perlahan tidak merusak rasa musikal yaitu dengan menggunakan grambyangan. Grambyangan yaitu awalan apabila ricikan gender barung akan beraksi melaksanakan buka gender untuk gending gender (Hastanto 2009). Grambyang dalam setiap perpindahan pathet menjadi sarana agar rasa suatu pathet dapat tercapai (Budi Prasetya 2012). Grambyangan dilakukan sebagai jembatan atau pintu masuk ke sebuah pathet oleh pengrawit agar tidak terikat dengan rasa pathet sebelumnya.

Dalam pakeliran peralihan pathet dilakukan oleh dalang menggunakan lagon dan gending yang disebut gending peralihan seperti Bondhet dan lagon seperti pada pathet nem menuju pathet sanga, pathet sanga menuju pathet manyura yaitu dengan menggunakan lagon pathet sanga wetah dan lagon pathet manyura wetah serta dengan menggunakan kayon seperti halnya kayon miring manengen 
pertanda pathet nem, kayon jejeg pertanda pathet sanga dan kayon miring mangiwa pertanda pathet manyura. Lancaran Gagak Setra dalam penyajiannya menggunakan transisi pathet, di dalam transisi pathet terdapat faktor musikal yang dipertimbangkan dalam transisi pathet.

Pathet nem menurut Srimulyana dalam pakeliran gaya Yogyakarta menitik-beratkan pada pathet sanga sedangkan gaya Surakarta menitik-beratkan pada pathet manyura. Pathet sanga dalam sajian pakeliran gaya Yogyakarta dalam ranah pathet nem tersebut dapat dilihat dari Lancaran Gagak Setra serta tlutur yang menitik-beratkan pada pathet sanga. Parjio berpendapat bahwa Lancaran Gagak Setra berlaras slendro pathet sanga serta digarap pathet sanga. Namun, ada beberapa asumsi yang menyatakan bahwa Lancaran Gagak Setra berlaras slendro pathet nem. Ada beberapa penelitian serta struktur pakeliran gaya Yogyakarta yang menyatakan lancaran tersebut pathet nem. Balungan gending menitik-beratkan pada pathet sanga. Berdasarkan beberapa asumsi tersebut maka, dalam penerapannya Lancaran Gagak Setra perlu adanya transisi pathet serta faktor musikal yang dipertimbangkan dalam transisi pathet agar peralihan pathet terjadi secara perlahan dan tercapai rasa pathet sanga pada Lancaran Gagak Setra seperti halnya grambyangan. Transisi pathet Lancaran Gagak Setra dapat dilihat pada adegan Paseban Jawi hingga adegan Perang Ampyak.

Berikut tabel transisi pathet Lancaran Gagak Setra:

Tabel 1. Pembagian Patet

\begin{tabular}{|c|c|c|}
\hline No. & Gending dan sulukan & Patet \\
\hline 1. & Ladrang Geger Sakutha & Nem \\
\hline 2. & Ada-Ada Laras Slendro Patet Nem Wetah & Nem \\
\hline 3. & Kawin Sekar Asmarandana & Manyura \\
\hline 4. & Bendhe Tengara & Manyura dan Sanga \\
\hline 5. & Kawin Sekar Pangkur & Sanga \\
\hline 6. & Lancaran Gagak Setra & Sanga \\
\hline 7. & Grambyangan Slendro Patet Nem & transisi \\
\hline 8. & Playon Lasem & Nem \\
\hline
\end{tabular}

Pathet nem di atas yaitu Ladrang Geger Sakutha dan ada-ada laras slendro pathet nem. Pathet nem bernada dasar atau dhong pada nada 2 (gulu) sedangkan pathet sanga bernada dasar atau dhong pada nada 5 (lima), pathet manyura bernada dasar atau dhong 6 (enem) (Martopangrawit 1975). Setelah penyajian pathet nem kemudian dilanjutkan Kawin Sekar Asmarandana laras slendro pathet manyura. Perlu diketahui sebelumnya bahwa kawin yang menggambarkan karakter dan kewibawaan tokoh wayang berdasarkan bentuknya dengan menggunakan metrum macapat yang disebut kawin sekar seperti suluk kawin sekar asmarandana, suluk kawin sekar pangkur dan sebagainya (Kasidi 2011). Kawin Sekar Asmarandana disajikan setelah sajian pathet nem karena perbatasan nada-nada pathet manyura dan pathet nem sangat tipis sehingga seseorang dapat keluar masuk dalam kedua pathet tersebut tanpa perlu adanya grambyangan. Suara Bendhe Tengara yang 
menjadi faktor musikal dalam transisi pathet manyura dan pathet sanga karena setelah penyajian Kawin Sekar Asmarandana dilanjutkan dengan Bendhe Tengara.

\section{Ungeling Bendhe}

$\begin{array}{cccccccccccc}6 & 2 & 6 & 2 & 6 & 6 & 2 & 6 & 3 & 5 & 6 & 2 \\ \text { Mung-jir } & \text { mung-jir trèt trèt trit trèt } & \text { trèt thèt thèt thèt } \\ 5 & 1 & 5 & 1 & 5 & 5 & 1 & 5 & 2 & 3 & 5 & 1 \\ \text { Mung-jir } & \text { mung-jir trèt trèt trit trèt trèt thèt thèt thèt }\end{array}$

Pathet manyura dan pathet sanga memiliki perbatasan nada-nada yang sangat tipis sehingga pathet manyura dapat langsung bertransisi menjadi pathet sanga dengan Bendhe Tengara oleh dalang dengan menurunkan nada dari nada 6 (nem) dan 2 (gulu) yang merupakan nada kempyung pathet manyura diturunkan satu nada menjadi 5 (lima) dan 1 (penunggul) yang merupakan nada kempyung pathet sanga. Setelah penyajian Lancaran Gagak Setra gending selanjutnya yaitu Playon Lasem. Playon Lasem berlaras slendro pathet nem. Perlu diketahui bahwa pathet nem dan pathet sanga memiliki jarak nada yang cukup jauh sehingga dalam penyajiannya, dua gending tersebut perlu adanya grambyang agar perpindahan pathet terjdi secara gradual tidak merusak rasa musikal dari kedua gending tersebut. Berikut grambyangan laras slendro pathet nem:

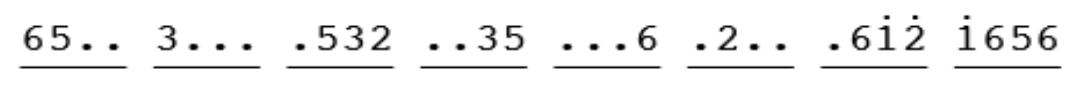

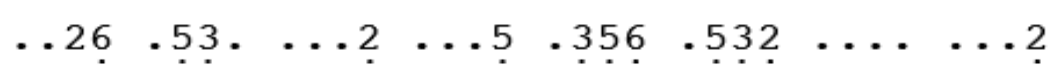

Pathet nem merupakan campuran pathet sanga dan manyura dapat dilihat dari struktur di atas bahwa ruang lingkup pathet nem dalam pakeliran terdapat pathet manyura dan pathet sanga. Pathet nem sangat dekat dengan pathet manyura, terbukti tidak ditemui cengkok seleh untuk gender, siter, dan gambang yang khusus untuk pathet nem (Budi Prasetya 2012). Pathet manyura sangat dekat dengan pathet sanga sehingga Lancaran Gagak Setra dapat tersaji melalui transisi pathet dengan faktor musikal yaitu Bendhe Tengara. Kemudian Playon Lasem, seperti di atas bahwa pathet nem jarak nadanya jauh dengan pathet sanga sehingga perlu adanya grambyang agar perubahan terjadi tidak secara mendadak faktor musikal yang dipertimbang kedua yaitu grambyangan. Pathet sanga dan pathet nem seperti pendapat Hangar Budi Prasetya sebelumnya bahwa perpindahan pathet sanga menuju pathet nem menggunakan grambyangan pathet nem dan berlaku dalam struktur sajian Lancaran Gagak Setra dalam pakeliran. Dimulai dari pathet nem kemudian pathet manyura dan kemudian pathet sanga dan grambyang selanjutnya pathet nem merupakan struktur dari transisi pathet Lancaran Gagak Setra.

Faktor musikal yang dipertimbangkan dalam transisi Lancaran Gagak Setra yaitu Bendhe Tengara dari pathet manyura menuju pathet sanga. Faktor musikal yang dipertimbangkan dalam transisi pathet yang kedua yaitu grambyangan yang dilakukan oleh gender sebelum disajikannya Playon Lasem. Semua itu dilakukan agar tercapainya rasa musikal yang akan mendukung unsur dramatik dari penyajian budhalan serta memberi transisi pathet yang lebih perlahan atau gradual. Berdasarkan kedua faktor tersebut ditemukan jawaban bahwasannya Lancaran Gagak Setra berlaras 
slendro pathet sanga yang mendukung unsur dramatik dari kapalan yang berkarakter gembira karena para tokoh budhal untuk mengiringi calon pengantin yang akan diadakan pesta nantinya.

\section{B. Analisis Pathet Lancaran Gagak Setra}

Analisis pathet Lancaran Gagak Setra berdasarkan pada teori nada gong atau seleh. Kedua teori tersebut menyebut bahwa nada dasar pathet sanga yaitu 5 (lima), pathet manyura 6 (nem), dan pathet nem 2 (ro) sebagai berikut analisis pathet Lancaran Gagak Setra:

Tabel 2. Analisis Patet

\begin{tabular}{|c|c|c|c|c|}
\hline \multirow{2}{*}{ Huruf } & \multicolumn{4}{|c|}{ Gatra } \\
\hline & 1 & 2 & 3 & 4 \\
\hline A. & $\begin{array}{r}.6 \cdot \overline{5} \\
\text { Sanga }\end{array}$ & $\begin{array}{l}\overline{3} \cdot \overline{2} \\
\text { Sanga }\end{array}$ & $\begin{array}{l}\overline{3} \cdot \overline{2} \\
\text { Sanga }\end{array}$ & $\begin{array}{r}.6 . \overline{5} \\
\text { Sanga }\end{array}$ \\
\hline B. & $\begin{array}{l}.6 \cdot \overline{5} \\
\text { Sanga }\end{array}$ & $\begin{array}{l}\cdot \overline{3} \cdot \overline{2} \\
\text { Sanga }\end{array}$ & $\begin{array}{l}\overline{3} \cdot \overline{2} \\
\text { Sanga }\end{array}$ & $\begin{array}{l}\cdot 6 \cdot \overline{\tilde{5}}^{i} \\
\text { Sanga }\end{array}$ \\
\hline c. & $\begin{array}{l}.6 . \overline{\mathrm{i}} \\
\text { Sanga } \\
\end{array}$ & $\begin{array}{l}. \breve{\underline{i}} . \overline{\mathrm{i}} \\
\text { Sanga }\end{array}$ & $\begin{array}{c}. \overline{\mathrm{i}} \cdot \overline{\mathrm{i}} \\
\text { Sanga }\end{array}$ & $\begin{array}{l}.6 \cdot \overline{\hat{5}}^{i} \\
\text { Sanga }\end{array}$ \\
\hline D. & $\begin{array}{l}.6 . \overline{\mathrm{i}} \\
\text { Sanga }\end{array}$ & $\begin{array}{l}. \dot{2} . \bar{i} \\
\text { Sanga }\end{array}$ & $\begin{array}{l}. \overline{2} . \overline{1} \\
\text { Sanga }\end{array}$ & $\begin{array}{l}\cdot 6 \cdot \overline{\tilde{5}}^{6} \\
\text { Sanga }\end{array}$ \\
\hline E. & $\begin{array}{l}. i . \overline{6} \\
\text { Sanga } \\
\end{array}$ & $\begin{array}{l}.3 . \overline{2} \\
\text { Sanga }\end{array}$ & $\begin{array}{l}.3 . \overline{2} \\
\text { Sanga }\end{array}$ & $\begin{array}{r}. \overline{6} \cdot \overline{5} \\
\text { Sanga }\end{array}$ \\
\hline
\end{tabular}

Pada Lancaran Gagak Setra menggunakan nada dasar atau dhong dari pathet sanga yaitu nada 5 (lima). Berdasarkan pada tabel di atas kolom A1, A2, A3, dan A4 menitik-beratkan pada pathet sanga. Kolom B1, B2, B3, dan B4 menitik-beratkan pada pathet sanga. Kolom C1, C2, C3, dan C4 menitik-beratkan pada pathet sanga. Kolom D1, D2, D3, dan D4 menitik-beratkan pada pathet sanga. Kolom E1, E2, E3, dan E4 menitik-beratkan pada pathet sanga. Setelah dianalisis pathet, Lancaran Gagak Setra memiliki satu rasa pathet yaitu pathet sanga. Kelima suwukan yang terdapat pada Lancaran Gagak Setra menggunakan nada dasar atau dhong dari pathet sanga yaitu nada 5 (lima). Berdasarkan analisis pathet ditemukan bahwa Lancaran Gagak Setra berlaras slendro pathet sanga.

\section{Analisis Garap Genderan}

Gender merupakan salah satu dari ricikan garap yang digunakan untuk menganalisis pathet Lancaran Gagak Setra. Permainan ricikan gender yaitu menggarap balungan gending (Mustika, n.d.). Ricikan gender dalam penyajian Lancaran Gagak Setra hanya dimainkan saat irama II setelah buka bonang yaitu satu setengah ulihan. Saat berubah menjadi irama I ricikan gender tidak 
dimainkan. Kemudian dimainkan kembali saat kapalan dengan dua ulihan. Lancaran Gagak Setra dalam pakeliran, penyajiannya dalam ranah waktu pathet nem setelah dianalisis balungan gendingnya Lancaran Gagak Setra menitik-beratkan pada pathet sanga. Dilihat pada analisis garap ricikan gender bahwa Lancaran Gagak Setra menitik-beratkan pada pathet sanga. Cengkok (pola lagu) yang diciptakan gender sering dapat menuntut pola lagu instrumentalis lainnya atau vokal (Sumarsam, 2018). Berikut analisis garap ricikan gender:

\begin{tabular}{|c|c|c|c|c|c|}
\hline No. & $\begin{array}{l}\text { Balungan } \\
\text { gending }\end{array}$ & & & Genderan & Cengkok \\
\hline 1. & $.6 . \hat{5} \cdot 3 . \hat{2}$ & $\frac{3536}{.323}$ & $\frac{3565}{5 \overline{65165}}$ & $\frac{\mathrm{i} 6 \mathrm{i} 5}{. \overline{165.5}} \frac{2356}{-656 \overline{612}}$ & $\underset{\text { cmpurn }}{G k 5+}$ \\
\hline 2. & $.3 \cdot \hat{2} \cdot \hat{6} \cdot \hat{\underline{5}}$ & $\frac{363 .}{.16 \overline{.56}}$ & $\frac{36632}{.16 \quad 5.2}$ & $\frac{-3.536}{2325} \frac{3565}{5 \overline{65165}}$ & $g k g$ \\
\hline 3. & $.6 . \hat{5} \cdot 3 . \hat{2}$ & $\begin{array}{llll}3 & 5 & 3 & 6 \\
. & 3 & 2 & 3\end{array}$ & $\frac{3565}{5 \overline{65165}}$ & $\frac{i 6 i 5}{.165 .5} \frac{2356}{-656 \overline{612}}$ & Gk5+cmpum \\
\hline 4. & $\cdot 3 \cdot \hat{2} \cdot \hat{6} \cdot \hat{a}^{i}$ & $\frac{3565}{-165.5 .}$ & $\frac{\overline{.6 .56} \mathrm{i}}{62 \overline{1616}}$ & 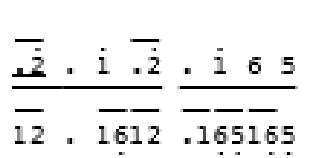 & Nauduk alit \\
\hline 5. & $.6 \cdot \hat{i} \cdot \check{i} \cdot \hat{i}$ & $\frac{i \cdot 6 i}{-61 \cdot 5}$ & $\frac{6 \cdot 65}{-61 \cdot 6}$ & $\begin{array}{lllll}\overline{.6 .5} & 6 \mathrm{i} & \overline{.6 .6 \mathrm{i}} \\
56 & 56 & & \frac{.7}{621616}\end{array}$ & Dllalit \\
\hline 6. & 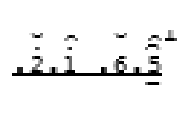 & $\frac{. \dot{2} \cdot \bar{i} \cdot \bar{i}}{\overline{12} \cdot \overline{16} \overline{12}}$ & $\frac{i 65}{\overline{21321}}$ & $\frac{3536}{-6535.2} \frac{3565}{-\overline{35235}}$ & Naudek 5 \\
\hline 7. & $.6 . \hat{i} . \check{i} \cdot \hat{i}$ & $\frac{i \cdot 6 i}{-61 \cdot 5}$ & $\frac{6 \cdot 65}{-61 \cdot 6}$ & 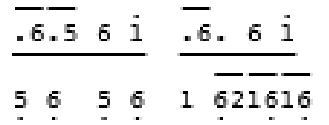 & Dll alit \\
\hline 8. & $\ddot{z} \cdot \hat{i} \cdot 6 \cdot \underline{\hat{5}}^{0}$ & $\frac{\overline{. \dot{2}} \cdot i \bar{i}}{\overline{12} \cdot \overline{16}}$ & $\frac{i 65}{. \overline{21321}}$ & $\frac{3536}{-6535.2} \cdot \frac{3565}{35235}$ & Naudek 5 \\
\hline
\end{tabular}

Pada baris 1 dan baris 3 menggunakan cengkok pathet sanga yaitu gendhuk kuning gembyang 5 (lima) dan cengkok campuran untuk seleh 2 ( $g u l u$ ). Pada baris 2 atau suwukan pertama menggunakan cengkok gendhuk kuning gembyang 5 (lima). Pada baris 4 atau suwukan kedua menggunakan nduduk alit 5 (lima) dengan kenong mlesed nada 1 (penunggul) alit karena balungan gending selanjutnya menitik-beratkan nada 1 (penunggul). Pada baris 5 dan baris 7 menggunakan cengkok dhua lolo alit dengan seleh 1 (penunggul). Pada baris 6 dan 8 atau suwukan ketiga dan keempat menggunakan cengkok nduduk 5 (lima). Baris 9 menggunakan cengkok $1 / 2$ dhua lolo alit dan seleh 2 (gulu). Gong atau baris 10 menggunakan cengkok tumurun. Berdasarkan analisis genderan di atas Lancaran Gagak Setra digarap dalam pathet sanga dengan mengacu pada ambah-ambahan balungan gending. Semua seleh menitik-beratkan pada seleh 5 (lima) dan 1 (penunggul) seperti pada kelima suwukannya. 


\section{Analisis Garap Rebaban}

Ricikan rebab merupakan ricikan yang menuntun arah lagu balungan gending serta vokal. Selama gending dimainkan, rebab memberi petunjuk arah alur lagu gending (Sumarsam 2018a). Wilayah nada rebab yang sepadan dengan wilayah nada gending maka ricikan rebab dapat meniru sifat lagu dari vokal. Penyajian ricikan rebab pada Lancaran Gagak Setra yaitu saat irama II seperti halnya pada ricikan gender setelah buka satu setengah ulihan dan saat kapalan dua ulihan. Berikut analisis garap ricikan rebab pada Lancaran Gagak Setra:

Tabel 4. Analisis Rebaban

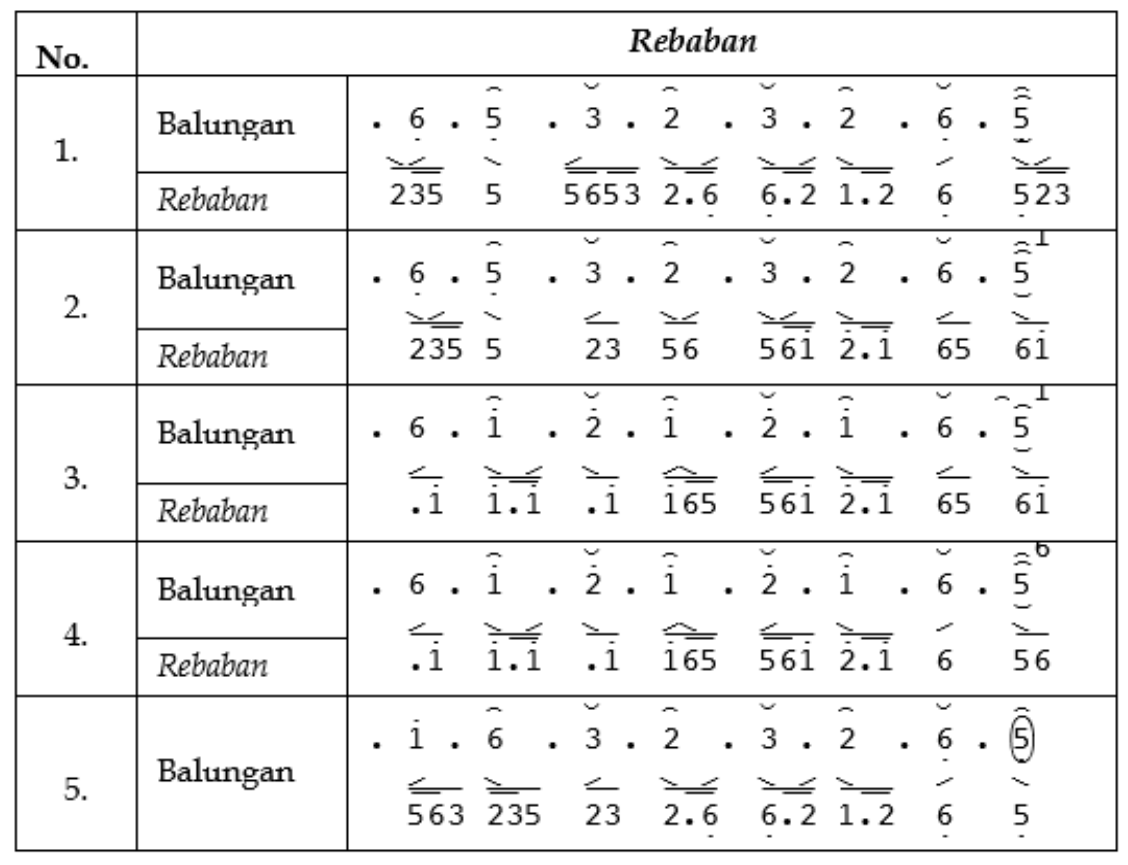

Garap ricikan rebab tersebut tidak menggunakan cengkok khusus. Ricikan rebab menitikberatkan pada pathet sanga yang mendominasi nada 1 (penunggul) dan 5 (lima) yang pada penggarapanya mengacu pada ambah-ambahan balungan gending. Ricikan rebab merupakan pamurba lagu sehingga ambah-ambahan rebab menuntun lagu dari balungan Lancaran Gagak Setra serta menuntun vokal.

\section{E. Analisis Garap Sindhenan}

Ambah-ambahan garap vokal atau sindhenan dalam Lancaran Gagak Setra mengacu pada garap ricikan rebab dan ricikan gender. Tidak ada garap khusus dalam garap vokal pada Lancaran Gagak Setra. Vokal mengisi pada gatra pertama hingga gatra keempat. Pada gatra pertama dan kedua menggunakan isen-isen dan pada gatra ketiga dan keempat menggunakan wangsalan yang dilakukan pada saat irama II yaitu setelah buka bonang satu setengah ulihan dan pada bagian kapalan dua ulihan. Wangsalan yang digunakan perlu mempertimbangkan padhang dan ulihan sesuai dengan sajian gendhingnya (Suparsih 2019). Berikut analisis garap sindhenan pada Lancaran Gagak Setra: 


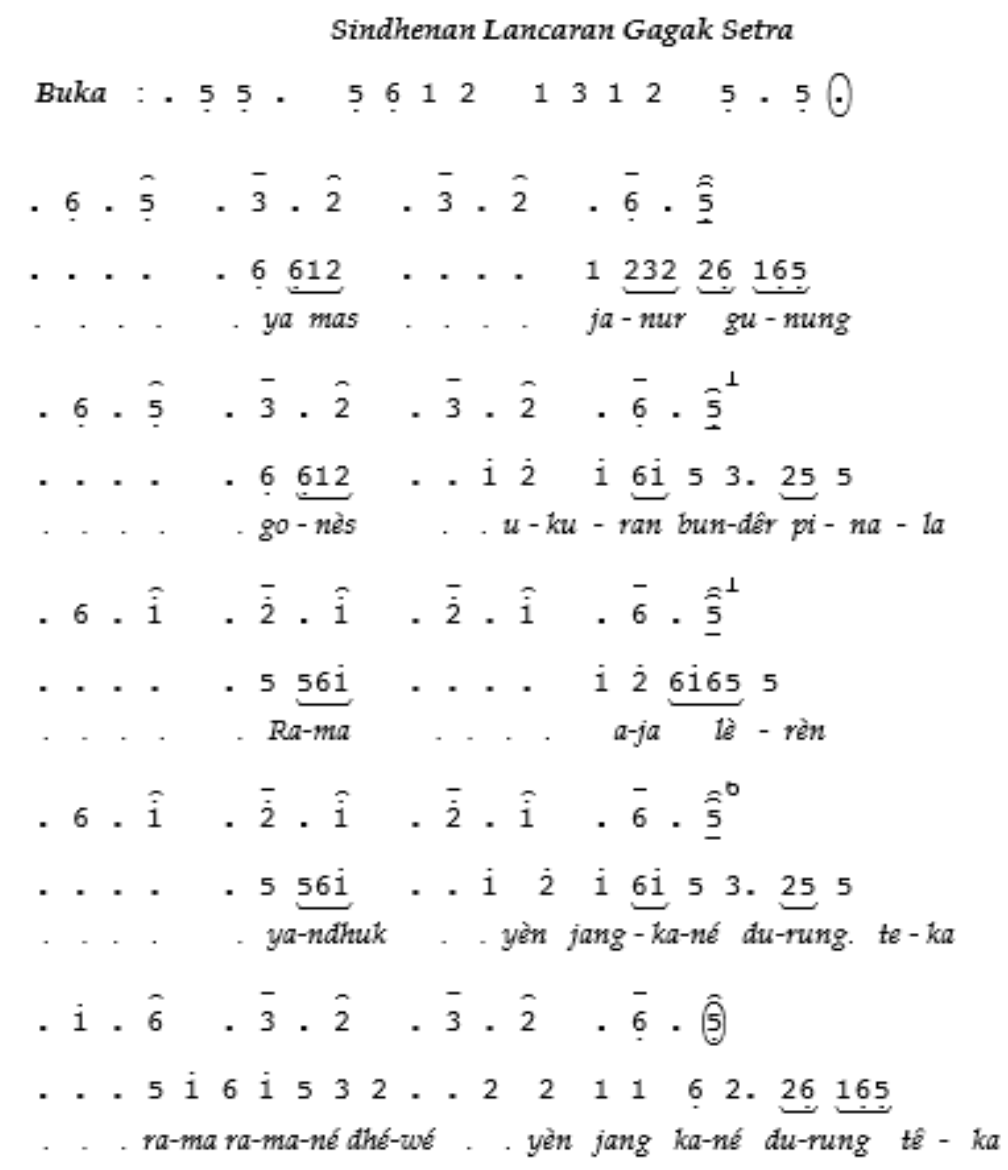

Pada garap vokal di atas menggunakan cengkok seleh slendro pathet sanga (Budiarti 2013) . Pada semua suwukannya menggunakan seleh 5 (lima) tengah dan 5 (lima) ageng. Ketiga garap sindhenan, garap rebab, dan garap gender menggunakan garap pathet sanga yang digarap seperti pada ambah-ambahan balungan gending.

\section{F. Analisis Garap Pekingan}

Permainannya peking gaya Yogyakarta dan Surakarta memiliki perbedaan. Peking gaya Surakarta dalam permainannya nginthili dan nikeli dari balungan gending sesuai dengan perubahan irama ketika irama lancaran nikeli 2 ketika irama dados nikeli 4 melipatkan tabuhan seperti saron, demung, dan slenthem. Peking gaya Yogyakarta dalam permainannya mendahului tabuhan dari ricikan saron, demung, dan slenthem dan hanya nikeli dua tabuhan saja dalam irama apapun (Arsadani 2021). Dalam sajian Lancaran Gagak Setra yang mengacu pada gaya Yogyakarta maka peking menjadi salah satu ricikan yang penulis pilih sebagai ciri khas dalam tabuhan ricikan balungan gaya Yogyakarta. Berikut analisis tabuhan peking dalam sajian Lancaran Gagak Setra: 
Tabel 5. Analisis Pekingan

\begin{tabular}{|c|c|c|c|c|c|}
\hline No. & \multicolumn{4}{|c|}{ Balungan Gending } & \multirow[t]{2}{*}{ Teknik } \\
\hline \multirow{2}{*}{1.} & . 6.5 & $\overline{3} \cdot \overline{2}$ & $\cdot \overline{3} \cdot \hat{2}$ & $\cdot \overline{6} \cdot \frac{\hat{5}}{5}$ & \\
\hline & $\begin{array}{llll}6 & 6 & 5 & 5\end{array}$ & $\begin{array}{llll}3 & 3 & 2 & 2\end{array}$ & $\begin{array}{llll}3 & 3 & 2 & 2\end{array}$ & $\begin{array}{llll}6 & 6 & 5 & 5\end{array}$ & Nikeli \\
\hline \multirow{2}{*}{2.} & $\cdot 6 \cdot \hat{5}$ & $\cdot \overline{3} \cdot \hat{2}$ & $\cdot \overline{3} \cdot \hat{2}$ & $\cdot \frac{-}{6} \cdot \hat{5}^{1}$ & \\
\hline & $\begin{array}{llll}6 & 6 & 5 & 5\end{array}$ & $\begin{array}{llll}3 & 3 & 2 & 2\end{array}$ & $\begin{array}{llll}3 & 3 & 2 & 2\end{array}$ & $\begin{array}{llll}6 & 6 & 5 & 5\end{array}$ & Nikeli \\
\hline \multirow{2}{*}{3.} & . $6 \cdot \hat{\hat{i}}$ & $\cdot \bar{i} \cdot \hat{i}$ & $\cdot \bar{i} \cdot \hat{i}$ & $\cdot \overline{6} \cdot \hat{3}^{1}$ & \\
\hline & 66 i i & $22 \mathrm{i} i$ & 22 i $i$ & $\begin{array}{llll}6 & 6 & 5 & 5\end{array}$ & Nikeli \\
\hline \multirow{2}{*}{4.} & $\cdot 6 \cdot \hat{\mathrm{i}}$ & $\cdot \bar{i} \cdot \hat{i}$ & $\cdot \bar{i} \cdot \hat{i}$ & $\cdot \overline{6} \cdot \underline{3}^{6}$ & \\
\hline & $\begin{array}{llll}6 & 6 & \mathrm{i} & \mathrm{i}\end{array}$ & $221 \mathrm{i}$ & 22 i $i$ & $\begin{array}{llll}6 & 6 & 5 & 5\end{array}$ & Nikeli \\
\hline \multirow{2}{*}{5.} & . $i \cdot \hat{6}$ & $\cdot \overline{3} \cdot 2$ & $\cdot \overline{3} \cdot \hat{2}$ & $\cdot \overline{6} \cdot \hat{5}$ & \\
\hline & i 166 & $\begin{array}{llll}3 & 32 & 2\end{array}$ & $\begin{array}{llll}3 & 32 & 2\end{array}$ & $\begin{array}{llll}6 & 6 & 5 & 5\end{array}$ & Nikeli \\
\hline
\end{tabular}

Peking saat irama I maupun irama II gaya Yogyakarta tidak berubah teknik tabuhannya tetap nikeli, dua kali tabuhan balungan. Teknik tabuhan peking akan berbeda, yang semula nikeli akan menjadi mbalung seperti ricikan demung ketika suwuk gropak yaitu terjadi dari empat gatra sebelum gong karena dalam sajian Lancaran Gagak Setra pada pakeliran gaya Yogyakarta menggunakan suwuk gropak. Berikut perubahan tabuhan pada ricikan peking ketika suwuk gropak:

\begin{tabular}{|c|c|c|c|c|c|c|c|c|}
\hline . $\mathrm{i}$ & $\hat{6}$ & 3 & $\hat{2}$ & .3 & . & & . & \\
\hline$i$ & 6 & 3 & 2 & 3 & 2 & 6 & 5 & Mbalung \\
\hline
\end{tabular}

\section{G. Analisis Garap Kendhangan}

Pertunjukan wayang kulit purwa merupakan cerminan kehidupan manusia dari lahir hingga tutup usia. Perjalanan hidup manusia tersebut divisualisasikan dalam sebuah pertunjukan wayang kulit dari bedol kayon hingga tancep kayon. Menurut Udreko (wawancara pada tanggal 22 Maret 2021) bedhol kayon dengan getar sebagai tanda dimulainya kehidupan. Ketika manusia telah lahir di dunia pastinya akan menghadapi berbagai rintangan di dunia. Rintangan yang dialami manusia salah satunya dengan simbol jaranan atau kapalan.

Adegan kapalan yaitu ketika salah satu tokoh wayang menaiki kuda. Adegan tersebut mempunyai makna orang yang sedang mengendalikan katuranggan atau hawa nafsu. Berhubungan dengan hal tersebut di dalam kendhangan kapalan terdapat beberapa sekaran yang menggambarkan seseorang sedang mengendalikan hawa nafsu. Manusia harus membuka keadaan (nyilakke kahanan) yang merintangi agar dapat dilalui. Dalam kendhangan kapalan, sekaran yang digunakan pertama yaitu nyigarada (nyilakke kahanan). Kedua yaitu adhean atau entrigan ketika 
manusia menata kehidupan haruslah berhati-hati. Setelah membuka keadaan yang merintangi, jalan akan lebih terpola. Pola tersebut tenyata harus dapat menyingkirkan empat nafsu atau meper nafsu papat diantaranya angkara, ludra, sukarda, nuraga sehingga sekaran ketiga yaitu sirig andhapan memiliki empat pola kendhangan yaitu $\mathrm{t} t \mathrm{p} d$. Setelah itu, manusia diharapkan untuk memilih mana yang bagus mana yang kurang bagus seperti halnya orang yang sedang nginteri beras. Saat seseorang sedang nginteri beras, beras yang bagus berada di tengah-tengah beras yang kurang bagus, sehingga pada sekaran keempat ini dinanamakan wedhikengser. Permasalah akan terus ada, di dalam perjalanan ada suatu hal yang merintangi seperti kayu, batu, pohon roboh. Permasalahan tersebut harus disingkirkan dalam adegan perang ampyak. Setelahnya selesailah permasalahan tahap pertama. Beberapa sekaran dalam kendhangan tersebut diterapkan saat kapalan yaitu ketika salah satu tokoh wayang berjoget di atas kuda dalam lakon Suryatmaja Krama tokoh wayang tersebut yaitu Aswatama. Ada beberapa gerakan wayang yang dilakukan ketika dalam kapalan seperti ulap-ulap, ngawe, ambegan, kentas, dan sebagainya. Terdapat empat sekaran dalam kendhangan kapalan yaitu nyigarada, adhean (entrigan), sirig andhapan, dan wedhikengser. Berikut beberapa sekaran kendhangan yang digunakan dalam kapalan:

Tabel 6. Sekaran Kendang

\begin{tabular}{|c|c|c|}
\hline No. & Sekaran & Kendhangan \\
\hline 1. & Nyigarada & $\overline{b \overline{b L}} \overline{k t} \overline{b \overline{b L}} \overline{k t}$ \\
\hline 2. & Adhean & $\overline{. t} \quad \overline{p t} \quad \overline{p t} \quad \overline{p t}$ \\
\hline 3. & Sirig andhapan & $\bar{t} \begin{array}{lll}t_{0} & \overline{\rho d} & \overline{0}\end{array}$ \\
\hline 4. & Wedhikengser & $\overline{. \overline{k t}} \overline{b \overline{\rho l}} \cdot \overline{k t} \overline{b \overline{\rho l}}$ \\
\hline
\end{tabular}

Sekaran tersebut digunakan ketika adegan budhalan yaitu ketika Aswatama menaiki kuda yaitu ketika irama II. Ada kurang lebih delapan belas ulihan dalam penyajian Lancaran Gagak Setra yang disajikan oleh Ki Udreko. Irama II disajikan selama empat ulihan yaitu kurang lebih dua ulihan pertama dan dua ulihan saat kapalan. Irama I disajikan dengan laya lancar ketika tokoh budhal dan laya seseg ketika rampogan. Kendhangan dengan teknik pinatut yaitu mengikuti kehendak dalang. Kendhangan tersebut diantaranya ketika Dursasana gejahan atau kiprah gaya Surakarta (Setiawan 2015).

\section{H. Analisis Garap Bonang Barung Dan Bonang Penerus}

Bonang barung dan bonang penerus dalam penyajian Lancaran Gagak Setra menjadi salah satu ricikan penentu dalam perubahan irama selain kendang. Permainan bonang barung dan bonang penerus dengan menggunakan teknik gembyang minjal pada saat kendang kalih, tabuhan imbal sekaran dengan teknik klenangan pada saat kendang batang dengan laya lancar, gembyang minjal pada saat irama I laya seseg kendang batang. Suwuk gropak menggunakan teknik mbalung dan gembyang midak. Teknik bonang penerus sama dengan teknik bonang barung hanya saja pada saat imbal bonang penerus mengimbalinya namun pada tabuhan imbal slendro sanga menggunakan 
teknik klenangan. Bonang yang memiliki pencon 10 khususnya gaya Yogyakarta imbal slendro sanga menggunakan teknik klenangan yaitu bonang barung menabuh 16 dan bonang penerus menabuh 32 secara bergantian mengikuti laya. Berikut contoh teknik tabuhan bonang barung dan bonang penerus ketika imbal sekaran dengan teknik klenangan dan gembyang minjal:

Tabel 7. Teknik Tabuhan Bonang Barung dan Bonang Penerus

\begin{tabular}{|c|c|}
\hline \multicolumn{2}{|c|}{ Imbal Sekaran dengan teknik klenangan ketika irama I } \\
\hline Bonang Barung & $16 \ldots 16 \ldots .5 .61615$ \\
\hline Bonang Penerus & $\begin{array}{lllll}\ldots 32 & \ldots 32 & \ldots 32 & \ldots 32\end{array}$ \\
\hline
\end{tabular}

\begin{tabular}{|l|llllllllll|}
\hline \multicolumn{8}{|c|}{ Imbal Sekaran dengan teknik klenangan ketika irama II } \\
\hline Bonang Barung & $\underline{16 \ldots}$ & $16 \ldots$ & $16 \ldots$ & $16 \ldots$ & $\underline{.5 .6}$ & .5 & $\ldots$ & .5 .6 & 1615 \\
\hline Bonang Penerus & $\ldots 32$ & $\ldots 32$ & $\ldots 32$ & $\ldots 32$ & $\ldots 32$ & $\ldots 32$ & $\ldots 32$ & $\ldots 32$ \\
\hline
\end{tabular}

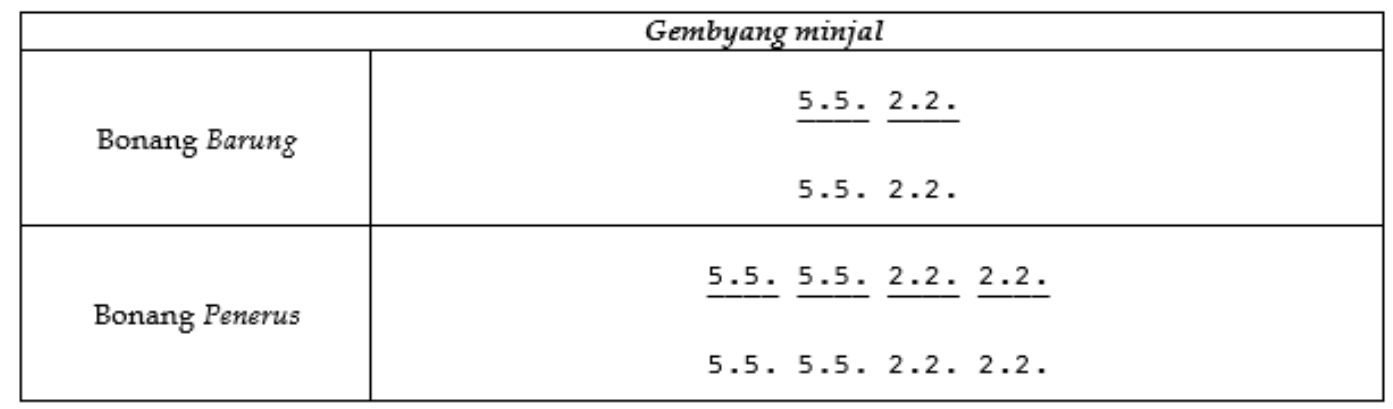

Bonang barung melakukan buka dan katampen kendang kalih dengan menggunakan gembyang minjal satu setengah suwukan kemudian dilanjutkan dengan imbal sekaran dengan teknik klenangan irama II. Ketika irama I menggunakan gembyang midak ketika laya seseg, ketika laya lancar menggunakan imbal sekaran dengan teknik klenangan (Supardi 2013).

\section{Kesimpulan}

Pathet nem merupakan pathet yang fleksibel karena pathet nem merupakan percampuran pathet manyura dan pathet sanga. Dalam pakeliran gending pathet manyura dan pathet sanga dapat disajikan dalam ranah waktu pathet nem. Terbukti dari struktur penyajian Lancaran Gagak Setra pada pathet nem kemudian pathet manyura, dan pathet sanga yaitu Ladrang Geger Sakutha, Kawin Sekar Asmarandana, Kawin Sekar Pangkur, dan Lancaran Gagak Setra kemudian kembali ke pathet nem yaitu Playon Lasem. Lancaran Gagak Setra dilihat dari balungan gending menitik-beratkan pada pathet sanga sehingga dalam penyajiannya lancaran tersebut perlu adanya transisi pathet, karena pathet nem dan pathet sanga memiliki sekat yang cukup kuat.

Transisi pathet tersebut berawal dari Kawin Sekar Asmarandana laras slendro pathet manyura, ada-ada nem wetah, Bendhe Tengara, Kawin Sekar Pangkur, dan setelahnya yaitu penyajian Lancaran Gagak Setra dilanjutkan dengan Grambyangan dan Playon Lasem. Berdasarkan transisi pathet tersebut ada beberapa faktor musikal yang dipertimbangkan dalam transisi pathet yaitu Bendhe Tengara dan grambyangan. Bendhe Tengara menjadi faktor musikal yang dipertimbangkan 
dalam transisi pathet manyura ke pathet sanga, grambyangan menjadi faktor musikal yang dipertimbangkan dalam transisi pathet sanga ke pathet nem.

Faktor musikal yang dipertimbangkan dalam transisi pathet Lancaran Gagak Setra membuktikan bahwa Lancaran Gagak Setra berlaras slendro pathet sanga yang diperkuat dengan garap Lancaran Gagak Setra yang digarap dalam pathet sanga. Asumsi mengenai Lancaran Gagak Setra berlaras slendro pathet nem dapat dilihat dari struktur penyajian Lancaran Gagak Setra memang disajikan dalam ranah waktu pathet nem sehingga asumsi tersebut dapat dilihat dari penerapan Lancaran Gagak Setra yang diapit oleh pathet nem diantaranya dari Paseban Jawi dengan Ladrang Geger Sakutha serta ada-ada dan pada adegan setelahnya yaitu perang ampyak dengan grambyangan pathet nem dan Playon Lasem. Analisis tekstual dalam penelitian ini membuktikan bahwa Lancaran Gagak Setra berlaras slendro pathet sanga dengan faktor musikal yang digunakan dalam transisi pathet yaitu Bendhe Tengara serta grambyangan.

Pada analisis kontekstual membuktikan bahwa Lancaran Gagak Setra berlaras slendro pathet nem pada struktur pertunjukan dalam pakeliran. Sehingga dua anggapan pathet mengenai Lancaran Gagak Setra memang benar adanya, namun beberapa asumsi serta penelitian terdahulu yang menyatakan Lancaran Gagak Setra berlaras slendro pathet nem dirasa kurang tepat, karena setelah dianalisis lebih menitik-beratkan pada pathet sanga. Penyajian Lancaran Gagak Setra dalam pakeliran yang berbeda pathet dari ranah penyajian dapat tercapai rasa pathet dari lancaran tersebut karena terdapat transisi pathet yang di dalamnya terdapat faktor musikal yang dipertimbangkan. Berdasarkan faktor musikal yang dipertimbangkan tersebut ditemukan jawaban bahwa Lancaran Gagak Setra berlaras slendro pathet sanga berkarakter gembira sesuai dengan karakter dari lakon Suryatmaja Krama pada adegan budhalan. Aliran pathet terjadi secara perlahan tidak merusak rasa pathet sebelum dan sesudahnya, sehingga penyajian Lancaran Gagak Setra menjadi suatu percampuran pathet yang selaras mendukung suasana dramatik dalam lakon Suryatmaja Krama pada adegan budhalan dengan menggunakan kapalan atau jaranan.

\section{Daftar Pustaka}

Arsadani, Robby. 2021. “Keragaman Pekingan Gaya Yogyakarta: Tinjauan Garap Dan Teknik Tabuhan." Institut Seni Indonesia Yogyakarta.

Bambang Sri Atmojo. 2011. Laporan Penelitian Kendhangan Pamijen Gending Gaya Yogyakarta. Yogyakarta: Lembaga Penelitian Institut Seni Indonesia Yogyakarta.

Budi Prasetya, Hanggar. 2012. "PathÃat: Ruang Bunyi Dalam Karawitan Gaya Yogyakarta." Panggung 22 (1): 67-82. https:/ / doi.org/10.26742/ panggung.v22i1.36.

Budiarti, Muriah. 2013. “Konsep Kepesindenan Dan Elemen - Elemen Dasarnya." Harmonia: Journal of Arts Research and Education.

Hastanto, Sri. 2009. Konsep Pathet Dalam Karawitan Jawa. Surakarta: ISI Press.

Junaidi. 2011. Wayang Sebagai Media Pendidikan Budi Pekerti Bagi Generasi Muda. Yogyakarta: CV. Arindo Kidul No. 20 Yogyakarta.

Junaidi, Junaidi, and Asal Sugiarto. 2018. “Hubungan Wayang Dan Gending Dalam Pakeliran 
Wayang Kulit Purwa Gaya Surakarta." Wayang Nusantara: Journal of Puppetry 2 (1): 19-27. https://doi.org/10.24821/wayang.v2i1.2998.

Kasidi. 2011. Setrukturalisme Dan Estetika Sulukan Wayang Kulit Purwa Pewayangan Gaya Yogyakarta. Yogyakarta: Badan Penerbit ISI Yogyakarta.

Martopangrawit. 1975. Pengetahuan Karawitan 1. Surakarta: ASKI Surakarta.

Mustika, Ema Mega. n.d. "Garap Gembyang Kempyung Dalam Genderan Gendhing Gaya Surakarta." ISI SURAKARTA.

Setiawan, Sigit. 2015. “Konsep Kendangan Pematut Karawitan Jawa Gaya Surakarta." Surakarta: Tesis Program Studi Pengkajian Seni Minat Musik ISI Surakarta.

Soeroso. 1985. Pengetahuan Karawitan. Yogyakarta: Proyek Peningkatan Pengembangan ISI Yogyakarta.

Soetarno. 2007. Estetika Pedalangan. Surakarta: ISI Surakarta dan CV. Adji.

Sri Mulyana. 1978. Wayang, Asal-Usul, Filsafat, Dan Masa Depannya. Jakarta: PT Gunung Agung.

Sumarsam. 2018a. Hayatan Gamelan. Yogyakarta: Gading.

- - - 2018b. Memaknai Wayang Dan Gamelan Temu Silang Jawa, Islam, Dan Global. Yogyakarta: Gading.

Supardi, Supardi. 2013. "Ricikan Struktural Salah Satu Indikator Pada Pembentukan Gending Dalam Karawitan Jawa." Keteg: Jurnal Pengetahuan, Pemikiran Dan Kajian Tentang Bunyi 13 (1).

Suparsih, Sri. 2019. “K;Asfikasi Dan Penerapan Wangsalan Dalam Pementasan Wayang Kulit Purwa Gaya Surakarta." Keteg: Jurnal Pengetahuan, Pemikiran Dan Kajian Tentang Bunyi. https:// doi.org/10.33153/keteg.v18i2.2401.

Umar Kayam. 2001. Kelir Tanpa Batas. Yogyakarta: Gama Media untuk Pusat Studi Kebudayaan (PSK) UGM dengan bantuan The Toyota Foundation.

Waridi. 2005. Bidang Seni Karawitan. Sekolah Tinggi Seni Indonesia (STSI); Pusat Studi Budaya \& Perubahan Sosial.

\section{Daftar Narasumber}

Margiyono, 70 tahun, dalang wayang kulit, pengendang wayang kulit dan Tenaga Pengajar (TPLB) di Jurusan Pedalangan Fakultas Seni Pertunjukan ISI Yogyakarta. Alamat: Kowen 1, Timbulharjo, Sewon, Bantul.

Marsudi Sanyoto, 69 tahun. Pengrebab wayang kulit purwa Ki Hadi Sugito, Ki Timbul Hadi Prayitno, Ki Sutono Hadi Sugito, Ki Wisnu Hadi Sugito. Alamat: Trisigan 2, Rt 03, Dk 4 Murtigading, Sanden, Bantul.

Mas Lurah Cermokartiko Sri Mulyono, S.Sn. 46 tahun. Pengajar Pamulangan Habirandha Yogyakarta. Alamat: Tamantirto Rt 6, Kasihan, Bantul. 
Parjio, 45 tahun, penggender wayang kulit Ki Hadi Sugito. Bertempat tinggal di Sebokarang, Wates, Kulon Progo.

Trusto (K.M.T Radyobremoro), 63 tahun, Staf Pengajar di Jurusan Karawitan FSP ISI Yogyakarta. Alamat: Kaloran, Bambanglipuro, Bantul.

Udreko Hadi Swasana, 53 tahun, Staf Pengajar di Jurusan Pedalangan FSP ISI Yogyakarta. Alamat: Gatak, Sumberagung, Jetis, Bantul.

\section{Diskografi}

Pertunjukan Wayang Kulit Purwa Lakon Suryatmaja Krama oleh dalang Ki Udreko Hadi Swasana. Pada tanggal 14 Februari 2021. Rekaman MP3 dan MP4 oleh Amrih Tuti Lestari. 